\title{
Certification of sustainable forest management systems: The importance of field verification ${ }^{1}$
}

\author{
by Russ Hughes ${ }^{2}$ R.P.F.
}

Certification requires an independent third party verification, commonly called an audit, to ensure that all components of a certification standard have been met. Field visits are an essential element to the Certification audit; however, the degree of field verification during the audit may vary depending on the objectives of the Sustainable Forest Management System. A key issue will be determining the proper balance between systems evaluation and field verification. Field audits establish credibility with the forest manager, the public and customers in addition to providing opportunities for training and public participation.

\section{Introduction}

Sustainable Forest Management (SFM) auditing is a relatively new concept and many of the criteria and standards are still being developed. The intent of this paper is not to concentrate on describing the audit process itself, but rather to discuss the importance of verification in the field. The paper begins by describing the elements of a SFM system and then discusses the issue of credibility. The remainder of the paper highlights the benefits of spending time in the forest during certification audits.

Independent verification of systems and management activities through third party audits are not an essential element of a Sustainable Forest Management System; but, they are a key aspect of the certification process. Independent audits assure stakeholders that certification standards are being met.

\section{Sustainable Forest Management Systems}

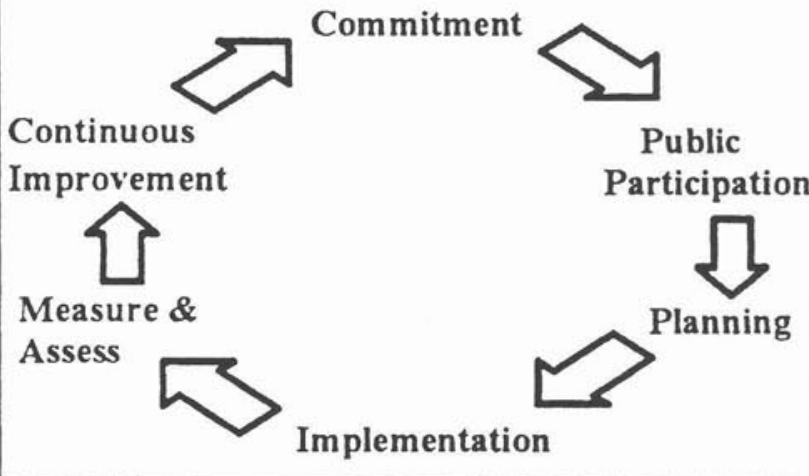

\footnotetext{
${ }^{1}$ Paper presented at the Canadian Institute of Forestry 88th Annual Meeting, Thunder Bay, Ontario, 20 August 1996.

${ }^{2}$ Price Waterhouse, Mississauga, Ontario, Canada L4Z 3M3.
}

La certification requiert la vérification indépendante par une tierce personne, ce qu'on appelle une vérification externe, afin de s'assurer que toutes les composantes de la norme de certification sont respectées. Les visites sur le terrain constituent un élément essentiel du processus de vérification externe au cours de la certification; cependant l'intensité des visites sur le terrain au cours du processus de vérification dépend des objectifs du système d'aménagement durable des forêts. Un élément clé réside dans l'identification d'un équilibre adéquat entre l'évaluation des systèmes et la vérification sur le terrain. Les vérification sur le terrain établissent un lien de crédibilité entre le gestionnaire forestier, le public, et les clients tout en constituant des occasions de formation et de participation du public

\section{SFM System}

The following diagram illustrates what is referred to as the SFM System Loop.

In order to successfully evaluate a SFM, the auditor or registrar must determine:

- to what extent the organization (both corporate and division levels) is committed to developing and implementing the SFM system. This includes not only reviewing the policy and management frameworks but also evaluating if the human and financial resources dedicated to this system are sufficient to meet the targets;

- if meaningful involvement of the public is the basis of the SFM system;

- whether the SFM targets are in conformance with the external standards, the relevant local regulations and the organization's own policies and objectives;

- whether the documentation system and monitoring procedures needed to ensure SFM targets are met, are in place;

- whether the targets are actually being met; and

- how the organization is constantly evaluating the inputs to the system.

\section{Credibility}

Although the foundation of a SFM system is built on effective public participation, the external credibility of the process lies in certification. Certification requires third party verification, commonly referred to as an audit. Audits are essentially a vehicle for evidence collection. The results of an audit are used to communicate compliance with the certification standard to employees, the community and to customers. The strongest audit evidence is derived from the results of the implementation of 
a SFM system, evidence that is found primarily in the forest. Therefore, it is hard to imagine a credible certification audit that does not include a visit to the forest that is being audited.

Forest visits also form part of the continuous improvement element, in that audit results must be considered credible by the forest manager. Therefore, it is a simple fact that to establish a credible process, one must verify these results by spending time in the forest during the audit.

Forest managers depend on documentation, clear and traceable plans and processes, and standard operating procedures to illustrate compliance. The development of management systems takes an enormous amount of time in the office. On the other hand, observation of field practices plays a key role in evaluating the implementation of forest management planning. It is an easy mistake to spend a disproportionate amount of time in the office rather than in the field during a certification audit.

\section{Field Verification}

During any audit, the evidence collected is based on a sample, due to time and resource constraints. Accessibility is an added element to the field portion of any forest audit. Many of the larger landscape values of a SFM system can be evaluated from the air; however, on-the-ground observations remain a major portion of the audit.

There are three major inputs into a SFM system which can be audited: the current state of the forest, public participation related to the development of the SFM system, and the management goals and objectives for the forest. (Bass 1995). All of these inputs require some form of verification in the field. This can vary from something as simple as determining if a specific mapped value, such as an eagle's nest, actually exists to evaluating whether a specific SFM objective such as habitat maintenance has been achieved.

\section{Regulatory Compliance}

Compliance with existing provincial and federal legislation and regulations is required to meet certification standards. For example the CSA Z808 Standard states,

The registration applicant must meet or exceed all regulatory standards, policies, and interpretations which apply to the defined forest area in order to have the Sustainable Forest Management System registered.

Other standards for certification will have similar statements.

Note that this is only one of the many requirements to comply with the standard. Certification goes beyond existing forestry legislation in Canada and, therefore, certification audits will have a much broader scope than compliance audits. A certification audit will not concentrate on regulatory compliance, but rather will require verification that an organization has the systems in place to prove compliance. This implies that the compliance monitoring or auditing will need to be done in advance of the certification audit.

Compliance audits, usually done by government agencies, are typically more concerned with field results than internal management systems. Many companies have established internal audit programs, supplemented by periodic external audits as part of their overall environmental management system. These audits focus on evaluating the implementation of the existing management system rather than on field results. Emphasis is placed on evaluating the internal checks and safeguards that are in place to ensure that company policies are being properly implemented and communicated to all staff.

Certification audits are, to some extent, a combination of both compliance and systems audits. The degree of field verification will vary depending on the values of the SFM system. During the field portion of a certification audit, evidence will be gathered on regulatory compliance. This may mean re-auditing an area that was audited during the compliance audit, or simply integrating compliance issues into protocols for the certification audit.

\section{Public Participation}

Public participation plays a role throughout the entire SFM system. Field audits provide an excellent opportunity to establish and maintain credibility with the local public advisory committee. By allowing representatives of the public to participate in the audit, it allows the public the opportunity to observe the audit process first hand, interact with the auditors, and learn more about the certification process.

Participation in the audit provides the public the chance to see some of the challenges that forest managers encounter when adhering to the objectives of the SFM systems. For example, establishing indicators that can be measured is a real challenge for some criteria such as biodiversity. In some cases, surrogate indicators will be used due to the lack of data or practical limitations on gathering this data. Many of these issues will be difficult to comprehend and can best be understood by observations made in the forest. This issue becomes very evident during the field portion of a certification audit. The development of a SFM system requires a significant amount of input from the public. We will need to take advantage of every opportunity to interact with these interest groups to maintain credibility and ensure this input is in keeping with sustainable forest management objectives.

\section{Management Goals and Objectives}

Through the public participation process, forest managers establish appropriate values and goals, choose indicators to measure these values and set objectives. A model is produced and the system is implemented. During the field portion of the certification audit, the auditor will verify the assumptions of the model and observe whether the system is achieving the desired results. As with any management system, it is rare that actual results are identical to what has been forecasted by the model. A large portion of the field audit will focus on assessing the effectiveness of procedures to measure results and implement the necessary improvements.

It is important to realize just what is currently verifiable in the field. Science has not developed to the point where auditors can measure the actual results of the Sustainable Forest Management System. Systems will be established to document the intended outcome, but this is only a forecast. As science progresses, the impact of results will become increasingly measurable. For example, one objective of a sustainable forest management system may be to maintain the population of pine marten. The performance indicator could then be the retention of suitable habitat for pine marten. Field verification would determine the successful implementation of this objective. Auditing the ultimate impact of the management activity, such as maintaining a mammal population, would be more difficult. This is due to 
the fact that the basic inventory information is not available or the link between the management objectives and the desired outcome is not well established. Through time, the impact on the sustainable resource, including incorporation of economic and social values, will be measurable and comparable.

\section{Training}

One of the more interesting aspects of a field visit is the opportunity to discuss the SFM system with field personnel. Certification standards require that employees, contractors, or members of organizations have an understanding of their roles and responsibilities in implementing the SFM system. This will require an investment in training by the organization.

The most effective manner in which to determine this requirement is to meet with field personnel while they are actually implementing the system. During the field portion of the audit, auditors have the opportunity to discuss the system with these parties and assess the effectiveness of the organizations' communication and training procedures.

\section{Conclusion}

Auditing SFM systems for certification is a very new process. The ultimate impact of sustainable forest management activities in the forest can only be assessed over a period of decades or perhaps longer. In the meantime, certification audits will focus on determining if SFM systems have been established and plans have been implemented in the field. Field verification is essential to maintain credibility with all involved, including auditors. Visits to the field are not only necessary to evaluate the effective implementation of the system but represent an additional opportunity to educate and promote certification.

\section{References}

Bass, S. and C. Upton, 1995. The Forest Certification Handbook, Earthscan Publications Ltd.

Canadian Standards Association "A Sustainable Forest Management System Z808 \& Z809".

Canada. 1992. Sustainable forests: A Canadian commitment. National Forest Strategy, Canadian Council of Forest Ministers.

Griss, P. 1996. Personal Communication.

Wedeles C. 1996. Personal Communication. 